\title{
Multi-taxon conservation in northern forest hot-spots: the role of forest characteristics and spatial scales
}

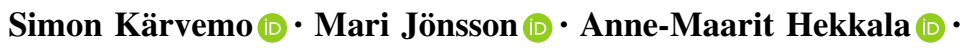 \\ Jörgen Sjögren $(\mathbb{D} \cdot$ Joachim Strengbom $(\mathbb{D}$
}

Received: 30 September 2020/Accepted: 28 January 2021 / Published online: 13 February 2021

(C) The Author(s) 2021

\begin{abstract}
Context Biodiversity is highly affected by industrial forestry, which leads to the loss and fragmentation of natural habitats. To date, most conservation studies have evaluated associations among a single species group, forest type, or spatial scale.

Objective The objective was to evaluate the richness of multiple species groups across various forest types and characteristics at multiple scales.

Methods We used the occurrence data for 277 species of conservation interest from 455 stands of high conservation value, including four species groups and four forest types.

Results Local, landscape, and regional forest characteristics influenced biodiversity in a non-uniform
\end{abstract}

Supplementary Information The online version contains supplementary material available at https://doi.org/10.1007/ s10980-021-01205-x.

S. Kärvemo $(\varangle) \cdot$ J. Strengbom

Department of Ecology, Swedish University of

Agricultural Sciences, Box 7044, 75007 Uppsala, Sweden

e-mail: simon.karvemo@slu.se

M. Jönsson

Swedish Species Information Centre, Swedish University of Agricultural Sciences, Almas Allé 8E, Box 7007,

75007 Uppsala, Sweden

A.-M. Hekkala · J. Sjögren

Department of Wildlife, Fish, and Environmental Studies,

Swedish University of Agricultural Sciences,

90183 Umeå, Sweden pattern among species groups and forest types. For example, an increased local spruce basal area in spruce forests was associated with higher vascular plant and bryophyte richness values, whereas macrofungi and lichen richness were positively correlated with deadwood availability, but negatively correlated with the spruce volume in the landscape. Furthermore, landscapes with twice as much mature forest as the average, had more than $50 \%$ higher richness values for vascular plants, macrofungi, and lichens.

Conclusion Among sessile species groups in northern forests, a uniform conservation strategy across forest types and scales is suboptimal. A multi-faceted strategy that acknowledges differences among species groups and forest types with tailored measures to promote richness is likely to be more successful. Nevertheless, the single most common measure associated with high richness across the species groups and forest types was mature forest in the landscape, which suggests that increasing old forests in the landscape is a beneficial conservation strategy.

Keywords Biodiversity - Bryophytes - Lichens · Macrofungi · Vascular plants · Woodland key habitats 


\section{Introduction}

Biodiversity is maintained by multiple interactions among biotic and abiotic factors that operate at multiple spatial scales. Differences in climate and land-use history generate large-scale species variation and this has been observed in many different biogeographical regions. However, the biotic interactions, including those related to habitat loss and fragmentation, determine variation at the landscape and local scale (e.g. Haddad et al. 2015; Newbold et al. 2016; Isbell et al. 2017). Thus, resources and processes operating at both the larger landscape scale (Poiani et al. 2000; With 2004; Thrush et al. 2013) and at local scales (e.g. Sverdrup-Thygeson et al. 2014; Nordén et al. 2018) will affect the occurrence and persistence of species. However, there is no consensus over the relative importance of local versus landscape processes as drivers of biodiversity (Hodgson et al. 2011; Fahrig 2013; Hanski 2015). Therefore, disentangling the importance of local and landscape effects would be highly beneficial to conservation management. Hence, there is a need to improve understanding about how different functional habitats (e.g. grasslands, wetlands, and old-growth forests) influence biodiversity and if such influence varies among species groups and over spatial scales (Poiani et al. 2000; Gonthier et al. 2014).

Anthropogenic land-use change mean that forest biodiversity is currently declining globally at an alarming rate (e.g. Bradshaw et al. 2009; Betts et al. 2017; Blowes et al. 2019). In many parts of the world, the introduction of industrial-scale forestry has fundamentally changed the forest landscape from multilayered and diverse stands towards high domination by even aged and structurally homogeneous stands (Östlund et al. 1997; Carnus et al. 2006). These changes are accompanied by reduced biodiversity (Hedwall et al. 2019), especially for old-growth forest organisms that are dependent on high forest structural complexity and large amounts of dead wood (Siitonen et al. 2001; Paillet et al. 2010). Continuity of habitat, in both space and time, is a prerequisite for the long-term persistence of all species. Organisms differ in functional traits, such as range size, dispersal capacity, and sensitivity to forest activities, which means that the biodiversity of different species groups may respond differently to the various intensities and spatial scales used by forest management programmes (Paltto et al. 2006). For sessile organisms, such as bryophytes, fungi, lichens, and vascular plants, variables associated with forest continuity is considered particularly important (e.g. Snäll et al. 2003; Jönsson et al. 2008; Johansson et al. 2012) and their dependence on this factor is commonly seen at rather small spatial scales (Sverdrup-Thygeson et al. 2014; Nordén et al. 2018). In addition, several studies indicate that the associated forest characteristics, such as mature forest, multilayered tree stands and deadwood, are more important for species richness than forest continuity per se (e.g. Ohlson et al. 1997; Nordén and Appelqvist 2001; Lõhmus and Lõhmus 2011; Rudolphi and Gustafsson 2011).

Conservation strategies to mitigate forest biodiversity losses include increasing the number and size of conservation areas, maintaining or increasing habitat heterogeneity at both the local and landscape scales, and ensuring connectivity among forest conservation areas (Morecroft et al. 2012). Preserving biodiversity through a network of conservation areas that contain high-quality habitats is a prioritised international target (e.g. CBD-Aichi Target 11; https://www.cbd. int/sp/targets/rationale/target-11/). The objectives for areas subjected to such conservation strategies generally focus on maximising biodiversity (Nicholson and Possingham 2006), even though conservation measures favouring some taxonomic groups may disfavour others. Thus, identifying forest characteristics that promote high species diversity, such as deadwood, older trees, and variable tree species composition, is considered important when attempting to meet conservation objectives and develop sustainable forest management programmes. Inherent in this process is that conservation managers will strive for a multi-scale approach in the spatial planning process (Poiani et al. 2000). Such plans, when restricted to an individual forest stand, or a conservation area, may be too small for the efficient management of certain species (Block et al. 1995; Poiani et al. 2000, but see Wintle et al. 2019). If forest conservation is to be improved, the guidelines that detail outcomes across different species groups and forest characteristics need to be produced at both local and landscape scales.

Northern European forests have been subjected to intensive forest management, which has resulted in the fragmentation of old-growth forests and deadwood (Kouki et al. 2001). Furthermore, it has been suggested that this fragmentation is the main cause of the ongoing decline in species richness (e.g. Dettki et al. 
2000; Stokland and Siitonen 2012; Sverdrup-Thygeson et al. 2014). A common strategy to mitigate such adverse effects is to exempt areas of conservation concern from forestry. In several northern European countries, small (often 3-5 ha) forest habitat patches with high biodiversity value, the so-called woodland key habitats (hereafter, key habitats), are set aside for the preservation of forest biodiversity (Timonen et al. 2011b; Wijk 2017). These key habitats are considered to be biodiversity hot spots based on their management history and forest composition (presence of old trees, large amounts of dead wood at many different decay stages, etc.), and commonly harbour species of conservation interest, such as vascular plants, bryophytes, macrofungi, and lichens. Such species are selected by expert panels, and are commonly associated with the rare features that occurs in key habitat, such as calcareous ground, dead and old trees or stable moist microclimate (Timonen et al. 2011b).

In this study, we utilised a unique data set from a national biodiversity survey conducted by the Swedish Forest Agency about the occurrence of several hundred species of conservation interest from vascular plants, bryophytes, macrofungi, and lichens (Wijk 2017). This data set enabled us to address how the biodiversity of multiple species groups varied among forest types and how the species groups were associated with tree species composition and the availability of key forest characteristics at the local and landscape scales. The main question for this study is: How is the species richness of different species groups associated with forest characteristics commonly considered in forest conservation planning? To answer this, we addressed how the species richness of vascular plants, bryophytes, macrofungi, and lichens of conservation interest differ in relation to the availability of forest characteristics at multiple scales. These characteristics are conservation areas, amount of dead wood, forest age, and tree-species composition. We considered their potential influence at the local and landscape scales. Furthermore, we addressed the importance of biogeographical regions (boreal vs. hemiboreal) and focal forest type, that is, whether the site was a deciduous-coniferous mixed, coniferous mixed, spruce-dominated, or pine-dominated forest type. As many of the studied species have a restricted dispersal capacity (Nordén and Appelqvist 2001), we hypothesised that key characteristics are more important at the local than at the landscape scale, and that the richness, in accordance with the latitudinal species gradient (Pianka 1966), will be higher in the southern hemiboreal region than in the northern boreal region. However, regional variations of important substrates, such as deadwood and mature forest may influence this pattern (Fridman et al. 2000).

\section{Material and methods}

\section{Field survey}

We examined data from 277 species consisting of vascular plants (58), bryophytes (52), macrofungi (99), and lichens (68) that are of conservation interest (see Online resource 1. for species identification). These species groups were selected primarily for this study because they are considered to signal forests of high conservation value, not too rare, and are generally easy to identify in the field. The data was obtained from a biodiversity monitoring program conducted by the Swedish Forest Agency, and were sampled by trained experts who were skilled in species identification (Wijk 2017; Nitare 2019). The samples were taken from 455 forested key habitats across a long latitudinal range (1300 km/latitude) that covered both boreal and hemiboreal biogeographical regions (Fig. 1). The Swedish boreal forest is highly dominated by Norway spruce (Picea abies L., Karst.) and Scots pine (Pinus sylvestris L.). Birch species (Betula spp.) are quite common, but scattered groves of ash (Fraxinus excelsior L.) and aspen (Populus tremula L.), and locally elm (Ulmus glabra Huds.), pedunculate oak (Quercus robur L.), and linden (Tilia cordata Mill.) occur in the southern hemiboreal region. Although Norway spruce and Scots pine are the dominant species in the hemiboreal (or boreonemoral) region, the above listed deciduous trees in this region are more widespread than they are in the boreal region. Landscape and local forest characteristics were extracted from satellite and field data, respectively. Species of conservation interest are commonly positively correlated with the number of red-listed species or overall high biodiversity (Gustafsson et al. 2004; Perhans et al. 2007; Timonen et al. 2011b; Mežaka et al. 2012). This was generally the case also in our study, where the number of species of conservation interest correlated significantly with the number of observations of red-listed species for all 


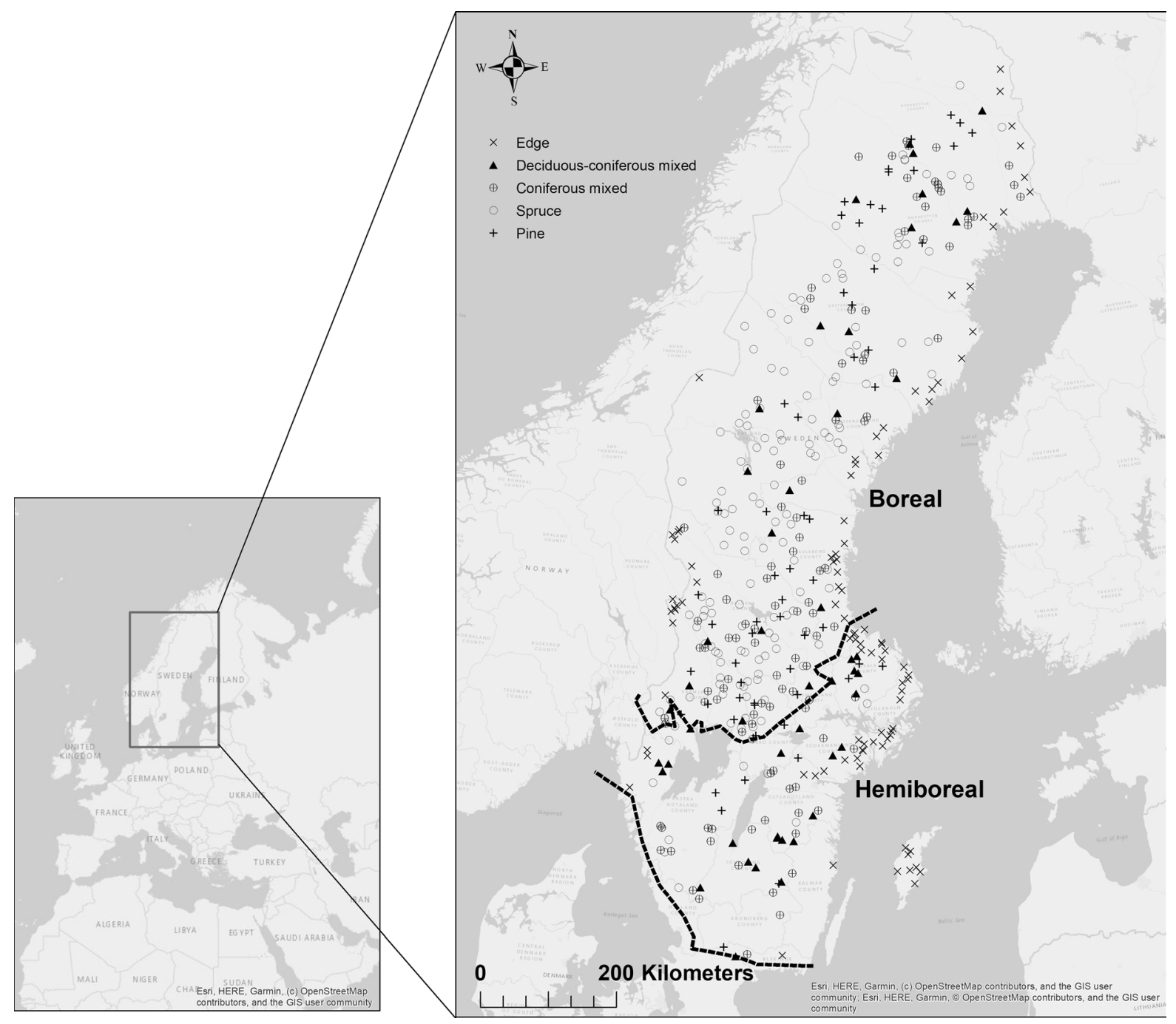

Fig. 1 Studied woodland types in Sweden, including edge sites (removed from the main models) and different biogeographical regions

species groups (Online resource 2). The same was true for the bryophyte and lichen species groups associated with deadwood and other substrates (Online resource 3). Exceptions were found for the macrofungal species group, where the number of species on deadwood and the number on other substrates were not positively correlated in three of four forest types. However, for these models, a relatively higher percentage of fungal species, was found on deadwood (73-83\%, dependent on the forest type), resulting in strongly biased data, and thus low model fits. Therefore, we expect that redlisted and deadwood species in general will respond similarly, and consequently we did not separate species of conservation interest and red-listed species, or species found on different substrates, in the subsequent analyses. The species surveys were conducted in areas up to 2 ha in size by dividing the area into subplots (for key habitats $<2$ ha, the entire key habitat was surveyed and for key habitats $>2$ ha, a representative 2 ha area was surveyed). The number of subplots surveyed varied between one and 20. Local forest characteristics were surveyed using $20 \mathrm{~m}$ long transects (4 $\mathrm{m}$ wide) and the number of transects varied between one and 18. The number of subplots and transects was strongly related to the size of the key habitat. A summary table of the species groups, variables, surveyed areas and forest types is shown in Online resource 4. 
Explanatory variables

The importance of forest characteristics at the landscape scale was analysed across $40 \times 40 \mathrm{~km}$ squares surrounding each key habitat. Mean volumes $\mathrm{ha}^{-1}$ of spruce, pine, deciduous trees, birch, and the area of mature forest (ha of forest with an age $>120$ years) were extracted from satellite images (Landsat EMT; Reese et al. 2003) taken in 2010 and validated from the ground by the Swedish National Forest Inventory (https://www.slu.se/nfi). These data were in the form of grid cell layers (rasters) with $25 \times 25$ m resolution. Since these data do not include logging operations that occurred after 2010, we created an additional layer containing information on all final felling that occurred during the period 2011-2018 (based on registrations at the Swedish Forest Agency). To further test the association between species richness and conservation areas in the landscape, we converged polygon data to raster data $(100 \times 100 \mathrm{~m})$ and used the summed area of forested reserves and woodland key habitats (based on data from the Swedish Forest Agency) in the surrounding $40 \times 40 \mathrm{~km}$ squares. Finally, we used data from the Swedish National Forest Inventory for the period 2014-2018 to evaluate deadwood volumes at the landscape scale. The deadwood data were converged to raster data $(100 \times 100 \mathrm{~m})$ from large squared polygons of different sizes ( 10,000-100,000 ha, including deadwood volumes $\mathrm{ha}^{-1}$ ), which were summed within the surrounding $40 \times 40 \mathrm{~km}$ squares. All landscape data were aggregated to $1 \times 1 \mathrm{~km}$ raster data by averaging tree species and deadwood volumes, and the conservation areas and areas of mature forest classified as older than 120 years were summed. This resulted in landscape data of 16,000 pixels surrounding each focal key habitat.

Comprehensive landscape data surrounding each key habitat was produced after removing sites close to the national borders of Sweden (within $20 \mathrm{~km}$, including sea and missing data from neighbouring countries), which left a total of 358 sites that used in our further analyses. The landscape data were interpolated into each site using a $40 \mathrm{~km}^{2}$ "moving window" approach (R package "raster": Hijmans 2017). A distance-weight function was added to each landscape variable by applying a Gaussian kernel filter within the $40 \times 40 \mathrm{~km}$ "moving window" using the "focalWeight" function in the R package "raster"
(Hijmans 2017). A sigma value of 7000 was chosen to correspond to a typical normal-distribution curve within the $40 \mathrm{~km}^{2}$ window, and was based on information from previously reported landscape associations with forest plants $(\sim 2 \mathrm{~km}$; Amici et al. 2015), macrofungi (1-3 km; Nordén and Larsson 2000; Edman et al. 2004b), and lichens (0.2-4.7 km; Ruete et al. 2014).

The landscape variables linked to each forest type were mirrored for the local variables, which meant that we could include field-surveyed local data about the basal area per hectare for spruce, pine, birch, and other deciduous trees when applicable. Local basal area per hectare for deadwood was included in all models. Data for these variables were sampled using transects (see "Field survey").

\section{Statistical analyses}

We analysed how the different biogeographical regions, landscapes, and local site factors (within key habitats) influenced the richness of the species of conservation interest within the four groups, which were vascular plants, bryophytes, macrofungi, and lichens. We ran separate analyses for each species group in four different forest type models: (i) deciduous-coniferous mixed forest (large numbers of deciduous trees), (ii) coniferous dominated mixed forest (dominated by spruce and pine), (iii) spruce dominated, and (iv) pine dominated (Table 1), which resulted in 16 different models. The species richness of the four species groups were additionally compared among the key habitat types and between sites located in the boreal and hemiboreal regions by applying sample-based rarefaction curves obtained using $\mathrm{R}$ package vegan (version 2.5-3; Oksanen et al. 2018). All 455 sites were included. A compilation of the species groups, model variables, and types of data are shown in Online resource 4.

All models included landscape data for the conservation areas and mature forests, whereas deadwood and tree species data were analysed at both the landscape and local scales. The conservation area, mature forest, deciduous, birch, and deadwood variables were $\log +1$ transformed to mitigate the effect of multiple outliers in the landscape data. The choice of tree species variables for each model was linked to the forest type in question (see Online resource 4). This resulted in nine variables for the deciduous- 
Table 1 Definitions of the four forest types surveyed

\begin{tabular}{lcccc}
\hline Forest types & Deciduous & Conifers & Spruce & Pine \\
\hline Deciduous-coniferous mixed forest & $40-60 \%$ & $40-60 \%$ & $<60 \%$ & $<60 \%$ \\
Coniferous-dominated mixed forest & $<30 \%$ & $>70 \%$ & $<70 \%$ & $<70 \%$ \\
Spruce-dominated forest & $<30 \%$ & $70-100 \%$ & $>70 \%$ & $<30 \%$ \\
Pine-dominated forest & $<30 \%$ & $70-100 \%$ & $<30 \%$ & $>70 \%$ \\
\hline
\end{tabular}

coniferous mixed (including living deciduous tree species variables) and coniferous mixed models (including living spruce and pine variables), and seven variables for the spruce (including living spruce variables) and pine models (including living pine variables).

We included site identity as a random effect in the generalised linear mixed models (GLMM) to reduce the effect of overdispersion and to control for possible variation associated with site-based spatial correlations. A Poisson distribution of errors was used to analyse the data because the response variables were species counts. Prior to each analysis, we checked the correlation matrices, including all continuous explanatory variables. None of the pairs had correlations $>0.7$ so we kept all the variables in the models (Dormann et al. 2013). To control for biogeographical differences in species numbers and uneven sampling effort, we included regions (boreal/hemiboreal) as categories and the size of the inventoried area as an offset in the models, which resulted in a rate dependent response. All continuous explanatory variables were standardised with means of zero and standard deviations of one. All models were fitted by optimising the model algorithm via the glmerControl "bobyqa" optimiser to rectify convergence problems (Powell 2009). This procedure minimises the model function of variables subjected to bound optimisation by quadratic approximation (Bates et al. 2015). To account for model uncertainty (e.g. variables with low weight) and increase the robustness of the variable estimates, we performed an unconditional model averaging (MuMIn package in R; Barton 2018), i.e. we used a weighted average of the estimates derived from the multiple variable combinations produced by each model. All models with a $\Delta$ AICc $>2$ compared to the best-fitted model were omitted to remove redundant and spurious models with very poor weights (Anderson and Burnham 2004; Grueber et al. 2011). Consequently, not all variables were included in all final models. Standard GLMM models were used to visualise predicted single variable effects by holding the other variables constant (function allEffects from the package "effects"; Fox 2003).

The data were processed and analysed in ArcMap 10.6 (ArcGIS, ESRI, Redlands, CA, USA) and R version 3.5.2 (R Development Core Team 2015).

\section{Results}

Biogeographical regions

Generally, in both biogeographical regions, differences among forest types (deciduous-coniferous mixed, coniferous mixed, spruce, and pine) followed the same pattern across species groups. Species richness was highest in spruce and/or the mixed forest types and lowest in pine forests (Figs. 2, 3). However, in the boreal region, spruce forests had a similar species richness as coniferous mixed forest for all species groups except for vascular plants (Fig. 2). Bryophyte richness was greatest in the deciduousconiferous mixed forests (Fig. 2b). In the hemiboreal region, the richness of macrofungi had the highest variation among forest types, being particularly high in spruce forests (Fig. 3c). Forests in the boreal region seemed to have a higher vascular plant, bryophyte, and lichen species richness than forests in the hemiboreal region. The macrofungi rarefaction curves never reached an asymptote in any of the regions, which suggested that increased sampling would generate higher species richness in the hemiboreal region. Differences among forest types were less distinct in the hemiboreal region than in the boreal region, which was probably due to the lower sample size and a relatively smaller geographic extent. Despite the sample size differences, the steeper accumulation curve at low sample sizes revealed a generally higher species richness in the boreal region compared to the hemiboreal region. 

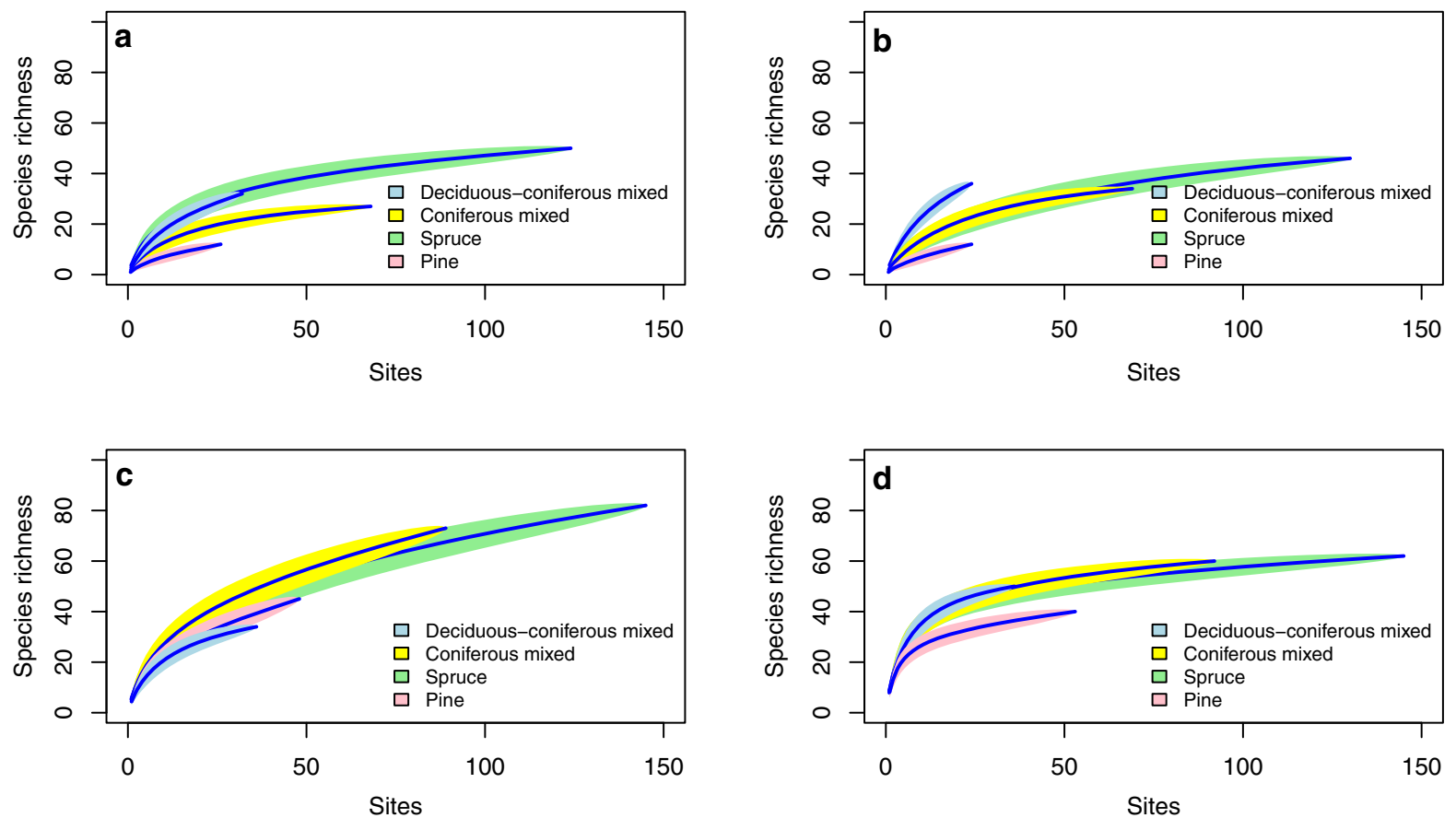

Fig. 2 Rarefaction curves for the species richness of a vascular plants, $\mathbf{b}$ bryophytes, $\mathbf{c}$ macrofungi, and $\mathbf{d}$ lichens in different forest types based on the number of sites sampled in the boreal biogeographical region
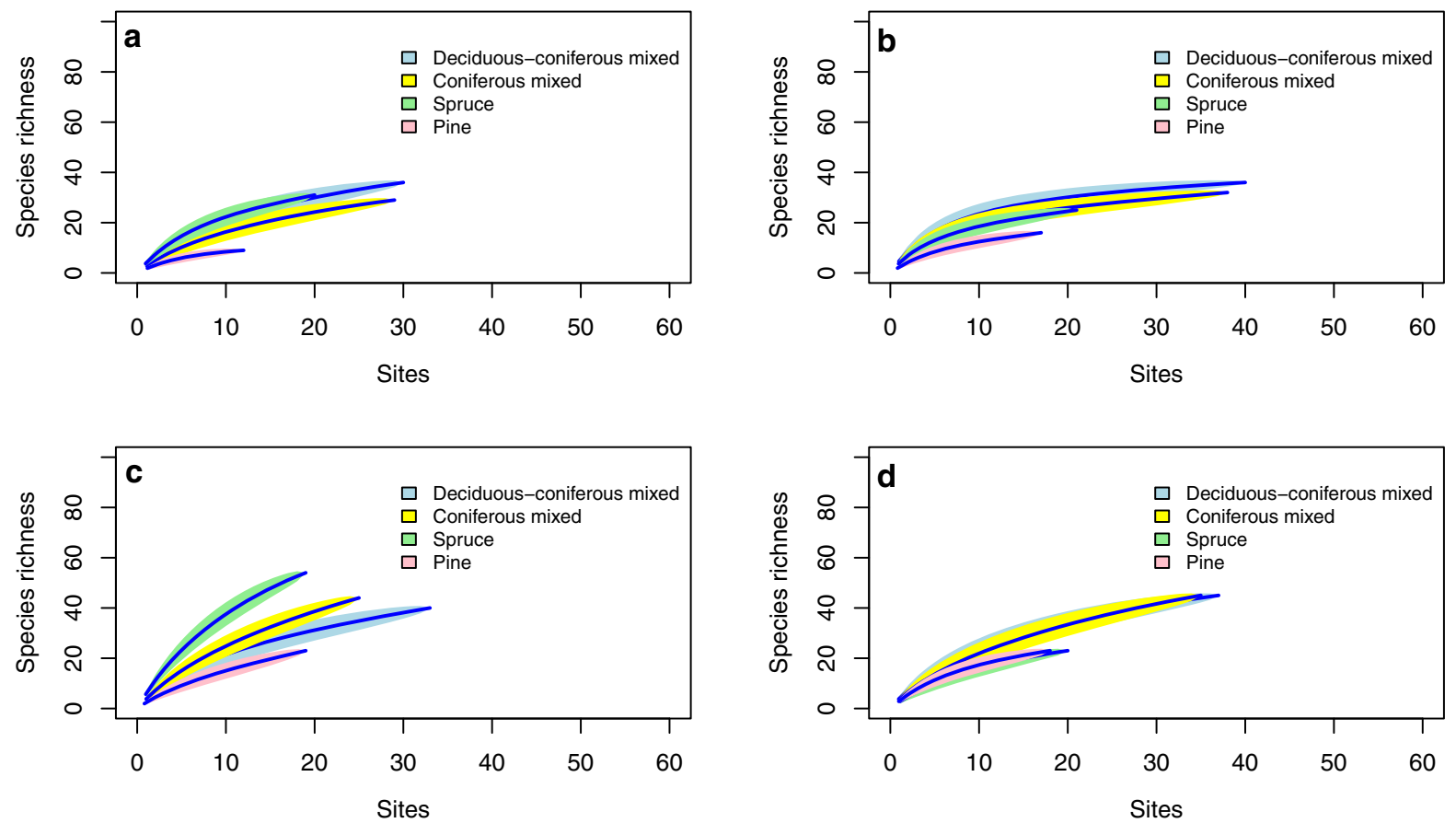

Fig. 3 Rarefaction curves for the species richness of a vascular plants, $\mathbf{b}$ bryophytes, $\mathbf{c}$ macrofungi, and $\mathbf{d}$ lichens in different forest types based on the number of sites sampled in the hemiboreal biogeographical region 
The results from the rarefaction curves corresponded somewhat with the results from the models. This can be exemplified by the significantly higher species richness of lichens and macrofungi in the boreal region compared to the hemiboreal region (based on three out of four forest type models for lichens and the coniferous-mixed forest type for macrofungi; Online resource 5). In contrast, bryophyte species richness in coniferous mixed forests was higher in the hemiboreal region than in the boreal region, but there were no significant differences in vascular plant richness among any of the forest types in either of the two regions.
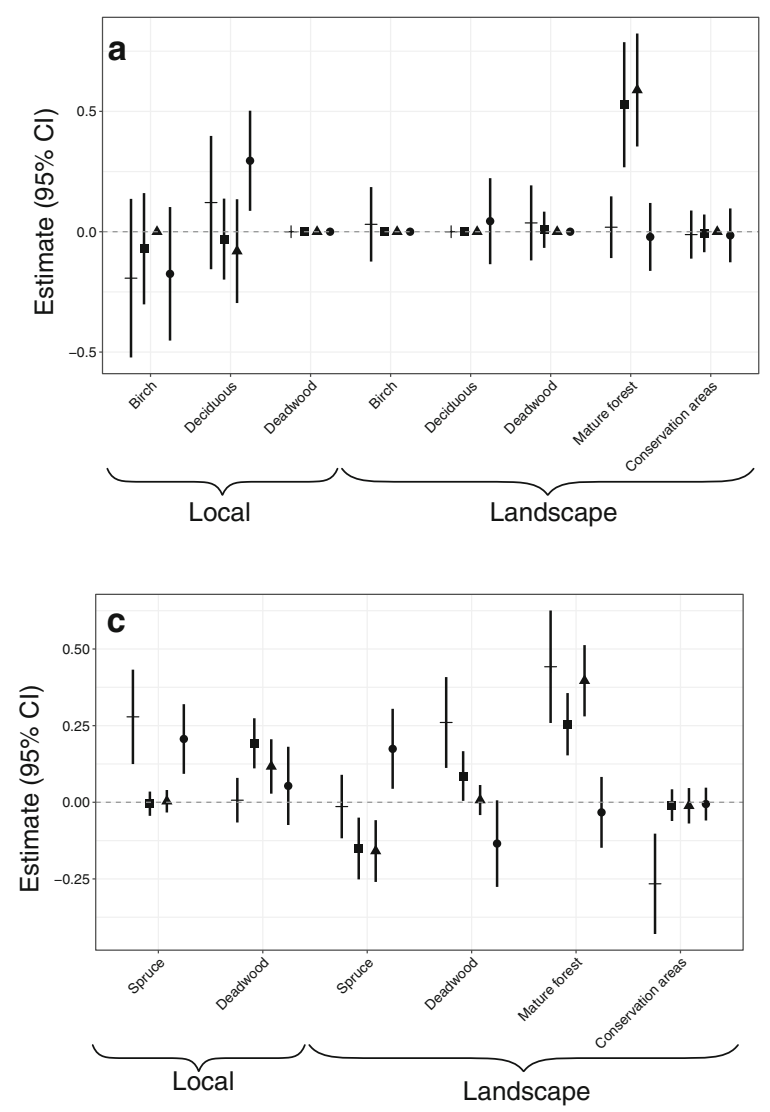

Fig. 4 Model estimates (95\% confidence intervals) for the different species groups: dagger-vascular plants, filled square-macrofungi, filled triangle-lichens, and filled circle-bryophytes associated with local and landscape variables in a deciduous-coniferous mixed, $\mathbf{b}$ coniferous mixed, $\mathbf{c}$ spruce,
Landscape factors

In general, the distribution of conservation areas in the surrounding landscape was a poor predictor of local species richness (Fig. 4a-c; detailed model results can be found in Online resource 5). One exception was in spruce-dominated forest types where vascular plant richness was negatively correlated with the extent of the conservation areas in the landscape (Fig. 4c). The area of mature forest ( $>120$ years) was a better predictor because the species richness of three out of four species groups, in at least one of the four forest types, was positively associated with the area of mature forest in the landscape. Specifically, lichen richness increased with increasing area of mature forests for all forest types (Fig. 4a-d). Richness of vascular plants and macrofungi in spruce and pine
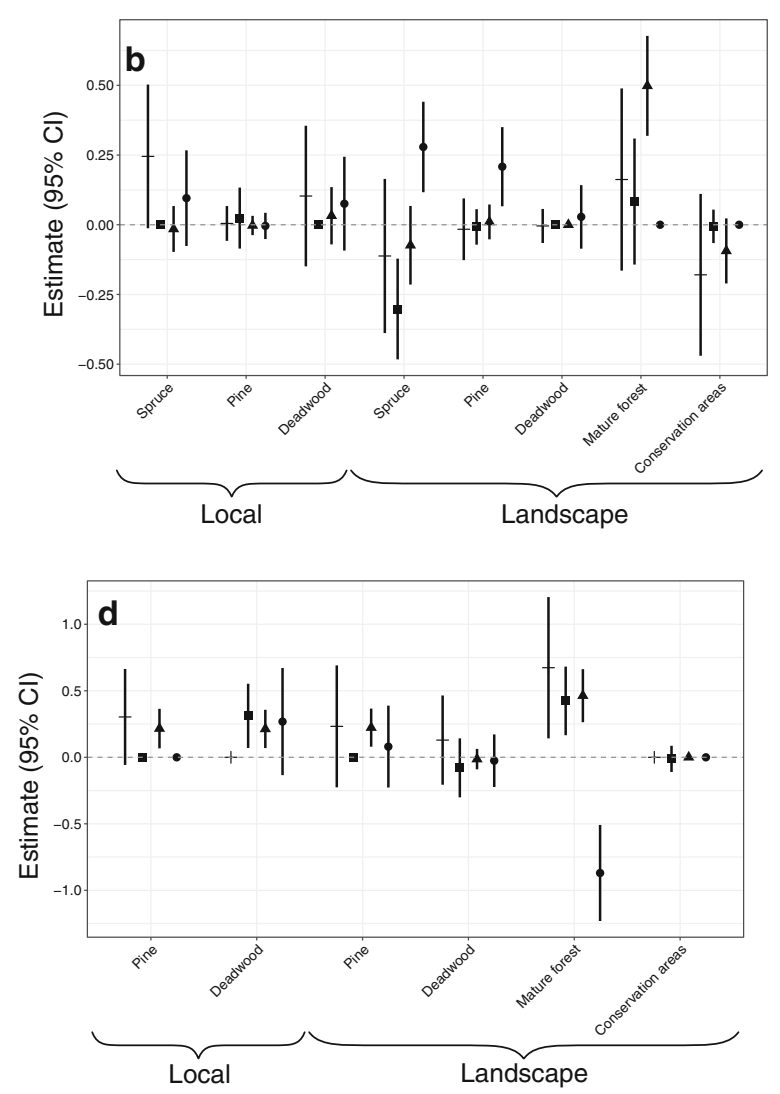

and $\mathbf{d}$ pine dominated forests. Variables with no effect and without error bars were not included in the final (averaging) models based on the criteria for deviation, which was more than two $\triangle \mathrm{AICc}$ from the best fitted model (see "Statistical analyses") 
forests was positively associated with the area of mature forests in the surrounding landscape (Fig. 4cd). In addition, macrofungal richness in the deciduousconiferous mixed forest type was also positively associated with the area of mature forest in the landscape (Fig. 4a). In contrast, bryophyte richness in pine forests showed no or even a strong negative association with the area of mature forest in the landscape (Fig. 4d).

The amount of dead wood was also important. The vascular plant and macrofungal richness in the spruce forest type was positively associated with the amount of dead wood in the surrounding landscape, but there was no association between deadwood and richness of lichens or bryophytes (Fig. 4). However, in the mixedconiferous and pine forest types, the richness of bryophytes and lichens was positively associated with the volume of pine in the landscape (exclusively included in the coniferous mixed forest type and pine models) (Fig. 4b, d). Furthermore, associations between species richness and spruce volumes in the landscape (exclusively included in the coniferous mixed model and spruce models) also differed among species groups. Generally, bryophyte species richness was positively related to spruce volumes in the landscape (Fig. 4b, c), while macrofungal and lichen species richness were negatively related with this variable in the coniferous mixed and/or spruce forest types, respectively (Fig. 4b, c). The volumes of deciduous or birch trees in the landscape were not associated with the richness of any of the species groups assessed in the deciduous-coniferous mixed forest type (Fig. 4a).

\section{Local factors}

In spruce and pine forests, lichen and macrofungal species richness increased with local deadwood amount (Fig. 4c, d; detailed model results can be found in Online resource 5). Likewise, lichen species richness in pine forests increased with local pine volume (exclusively included in the coniferous mixed model and pine models; Fig. 4d). In spruce forests, species richness of vascular plants and bryophytes were higher in areas with higher basal areas of local spruce (exclusively included in the coniferous mixed model and spruce models; Fig. 4d). The bryophyte richness also increased with the basal area of local deciduous trees in deciduous-coniferous mixed forests
(Fig. 4a), whereas the basal area of local birch was not associated with any of the species groups in any forest type. The macrofungal species richness was not associated with any of the local live tree variables.

\section{Discussion}

This study demonstrates multifaceted biodiversity relationships among groups of species of conservation interest, and their associations with forest characteristics at multiple scales and different forest types. Our results concur with studies suggesting that both local and landscape factors can be drivers of diversity (e.g. Gonthier et al. 2014; Sverdrup-Thygeson et al. 2014). However, our results also highlight that there appears to be no simple general pattern for the local diversity of different species groups in various forest types in relation to local and landscape factors. This complicates conservation efforts because optimal conservation strategies must consider the biogeographical region in question, the target-specific forest type, and forest management regimes at different spatial scales to best support successful outcomes for biodiversity.

For example, species richness of bryophytes was higher in the coniferous-mixed forests in the southern hemiboreal region than in the northern boreal region. In contrast, the coniferous mixed, spruce, and pine dominated forest types in the boreal region had a higher richness of macrofungal and lichen species than forests in the hemiboreal region. This may seem counterintuitive to the latitudinal diversity gradient, where species richness is hypothesized to increase towards the south as a result of milder and more stable climate, increasing habitat, productivity and growth season (sensu Pianka 1966). However, the longer forest management history in the hemiboreal region has probably reduced the biodiversity of many species groups in that region of Sweden (Nilsson 1992). This highlights that even within a single biogeographic region, the preservation of biodiversity cannot rely on a common and uniform strategy that encompasses different species groups and forest types.

The availability and spatial distribution of habitat resources in the landscape may interact with the habitat resources at local scale, and affect species differently depending on their dispersal capability (e.g., Ranius et al. 2019). Species capable of longdistance movement, such as birds and insects, are 
commonly affected by the availability of resources at both local and large spatial scales (Lindenmayer and Franklin 2002). A local increase in habitat, such as deadwood for saproxylic organisms, may generate greater increases in beetle species richness (Rubene et al. 2017) and red-listed wood fungi (Nordén et al. 2018) in landscapes with a lot of deadwood. The species included in our study were sessile species dependent on wind or vector-assisted dispersal of asexual and sexual propagules, with local species richness likely dependent on a combination of higher depositions of propagules from local sources and higher habitat amounts (e.g., Edman et al. 2004a, b). This meant that we, in accordance with other studies (Poiani et al. 2000; Aune et al. 2005; Paltto et al. 2006), expected local characteristics to have a stronger influence than landscape forest characteristics. Accordingly, bryophyte species richness was positively associated with the local basal area of deciduous trees, whereas deciduous volume at the landscape scale was a poor predictor of local bryophyte richness. However, spruce and pine in the mixed-coniferous forest were positively associated with bryophyte richness at the landscape, but not at the local scale. Furthermore, in the pine and spruce forest types, high species richness of macrofungi and lichens were associated with high amounts of dead wood at both the local and landscape scales, whereas vascular plant richness increased only with increasing amounts of dead wood at the landscape scale. Thus, we could not find a general support for a higher importance of forest characteristics at local scales compared to landscape scales. However, the results suggest that compared to bryophytes and vascular plants, macrofungi and lichens show stronger association with variables associated with forest continuity, such as deadwood and old trees (e.g. Dettki et al. 2000; Mežaka et al. 2012; Stokland and Siitonen 2012).

We also found the highest proportion of macrofungal and lichen species on deadwood, whereas e.g. bryophytes were commonly found on other substrates (see Online resource 3). Therefore, despite the complex nature of our results, they indicate that it is easier to find variables describing forest characteristics that predicts richness of macrofungi and lichens (12 and nine, respectively) than vascular plants and bryophytes (five and seven, respectively). This can be illustrated by a much higher proportion of macrofungal and lichen specialist species, compared to vascular plants and bryophytes (Nordén et al. 2013; StaniaszekKik et al. 2019). This was also true for the spruce and pine forest types (14 and nine forest characteristic variables, respectively), but not to the same extent for the mixed tree species types (five for deciduousconiferous mixed and seven for coniferous-mixed forests). This suggests that macrofungi and lichens are more affected by variables associated with forest loss and fragmentation (Arroyo-Rodríguez et al. 2020 and references therein), and that it is consequently easier to identify conservation strategies for these species groups than for bryophytes and vascular plants. On the contrary, bryophytes and vascular plants may be more dependent on soil characteristics and a stable humid microclimate to maintain high levels of richness (De Frenne et al. 2013; Fenton et al. 2015). Such environmental variables are typically not measured in forest biodiversity surveys, and were also not measured and tested in our study focusing on forest structural variables. Our results also suggest that, in general, it may be easier to promote species richness in spruce or pine dominated forests than in mixed forests.

Richness of all species groups, but bryophytes, increased as the proportion of mature forests in the surrounding landscape rose. This finding agrees with previous studies, which demonstrate that colonisation by epiphytic lichens (Dettki et al. 2000; Johansson et al. 2012), wood-decaying fungi (Edman et al. 2004a, b; Nordén et al. 2013), and vascular plants (Matlack 1994; Varela et al. 2018) is higher in landscapes with a high proportion of older forest, but failed to support the findings by Rudolphi and Gustafsson (2011), who found that species richness of bryophytes of conservation interest increased with larger areas of old forests in the surrounding landscape. The strong positive association between species richness and surrounding mature forest, and the observed negative relationship with high tree volumes of surrounding spruce stands were probably caused by a positive correlation between managed homogenous spruce forests and high volumes and stem densities of relatively young spruce trees (Table 7 in Anonymous (2018)). This result confirms the strong negative effects of intensive forest management on species diversity (Lassauce et al. 2011; Kouki et al. 2012). Our results also support the idea that maintaining or increasing forest age in the landscape can be an effective strategy to support richness of species of conservation interest. This is in accordance with 
Roberge et al. (2018), suggesting that species requiring older forest would generally be positively affected by extended rotations. Although our results highlight the importance of older forests in the landscape, we found no support for the idea that a high proportion of conservation areas in the landscape promote local species richness. This might appear surprising as these conservation areas are known to have a higher-thanaverage biodiversity (Paillet et al. 2010; Timonen et al. 2011a; Hekkala et al. unpublished), and that aggregation of such areas into certain landscapes is a commonly recommended conservation strategy (Lindenmayer and Franklin 2002; Morecroft et al. 2012). The weak association between species richness and conservation areas in the surrounding landscape indicate that the landscape configuration for these species groups in conservation areas might be unimportant (Fahrig 2013) or, alternatively, that the fragmentation is so recent that the forest included in our study suffer from a large extinction debt (Berglund and Jonsson 2005; Paltto et al. 2006). A similar result will occur if there are too few conservation areas, or if they are too fragmented to maintain the patch networks needed to promote high richness levels for the studied species (Aune et al. 2005). The latter is in accordance with the clear positive effect of mature forests, where the mean percentage in the landscapes surrounding the different forest types studied was $15-24 \%$ whereas the corresponding percentage for conservation areas was $6-8 \%$.

\section{Conclusions for practice}

This study illustrates the challenges of adapting forest conservation measures to multiple species. Our results show that important forest characteristics at the local, landscape, and regional scales influence biodiversity in a non-uniform pattern among species groups and forest types. Although both local and landscape variables were associated with local richness, the forest characteristics important at the local scale often differed from those important at the landscape scale. This finding needs to be reflected in conservation strategies aiming at increasing structural diversity. Biodiversity, forest characteristics, and management history commonly differ among regions. Although it is a common recommendation that such factors should be considered when planning conservation strategies, the empirical support to back such claims has so far been limited. Since our study include more species groups, a larger number of stands, and cover a larger geographical area than most other studies, our results add important empirical support for this claim. Despite that our data can not reveal the mechanistic explanations as to why these patterns occur, we conclude that the general productivity-diversity pattern observed for common species (e.g. Chase and Leibold 2002; Gillman and Wright 2006) also appears to be valid for the relationship between local productivity and diversity of species of conservation interest. Our finding that sites with higher spruce basal areas contain more bryophytes and vascular plants of conservation interest (Online resource 6a, 7a, 8a), suggests that if the goal is to safeguard diversity in the managed forest landscape, then it is important that high-productivity forests are well represented among the set asides. Currently, forests that are set aside for the preservation of biodiversity are commonly biased towards low productivity sites (Fridman 2000; Scott et al. 2001). In addition, our results suggest that a strategy that includes high productivity sites in conservation areas is not likely to favour the conservation of macrofungi and lichens. These groups (together with vascular plants) are more likely to respond positively to a landscape conservation approach that aims to set aside forests in areas with e.g. a high proportion of mature forest (Online resources $9 \mathrm{~d}$, and $10 \mathrm{e}$ ). The finding that species groups were associated with different local and landscape variables highlights the importance of developing more differentiated conservation approaches that encompass species-specific demands at several spatial scales. In this context, our study recommends progressive landscape planning for biodiversity conservation, simultaneously considering both local and landscape goals for multiple species groups (Michanek et al. 2018). One must take into consideration that the results presented in this study may have multiple causal effects, and that variables such as productivity and historical land use may influence the result. Moreover, differences in forest structures may be associated with additional microclimatic variables that were not included in this study, e.g. canopy cover, humidity, $\mathrm{pH}$, soil characteristics, sun exposure and temperature (Esseen et al. 1997), which in turn may be associated with the species richness of the studied species groups (e.g. Frahm 
2003; Zinko 2004; Pouska et al. 2016). In this context, our study needs to be followed by additional studies that clarify the importance of such factors.

Acknowledgements We thank Olle Kellner and Neil Cory at the Swedish Forest Agency for providing the data. This work was supported by the Swedish Research Council for Environment, Agricultural Sciences, and Spatial Planning [Project 2016-20029].

Open Access This article is licensed under a Creative Commons Attribution 4.0 International License, which permits use, sharing, adaptation, distribution and reproduction in any medium or format, as long as you give appropriate credit to the original author(s) and the source, provide a link to the Creative Commons licence, and indicate if changes were made. The images or other third party material in this article are included in the article's Creative Commons licence, unless indicated otherwise in a credit line to the material. If material is not included in the article's Creative Commons licence and your intended use is not permitted by statutory regulation or exceeds the permitted use, you will need to obtain permission directly from the copyright holder. To view a copy of this licence, visit http://creativecommons.org/licenses/by/4.0/.

Funding Open access funding provided by Swedish University of Agricultural Sciences.

\section{References}

Amici V, Rocchini D, Filibeck G, Bacaro G, Santi E, Geri F, Landi S, Scoppola A, Chiarucci A (2015) Landscape structure effects on forest plant diversity at local scale: exploring the role of spatial extent. Ecol Complex 21:44-52

Anderson D, Burnham K (2004) Model selection and multimodel inference, 2nd edn. Springer, New York

Anonymous (2018) National forestry accounting plan for Sweden. Ministry for the Environment and Energy Government offices of Sweden, Stockholm

Arroyo-Rodríguez V, Fahrig L, Tabarelli M, Watling JI, Tischendorf L, Benchimol M, Cazetta E, Faria D, Leal IR, Melo FP (2020) Designing optimal human-modified landscapes for forest biodiversity conservation. Ecol Lett 23:1404-1420

Aune K, Jonsson BG, Moen J (2005) Isolation and edge effects among woodland key habitats in Sweden: is forest policy promoting fragmentation? Biol Conserv 124:89-95

Barton K (2018) MuMIn: Multi-Model Inference, R package version 1.42.1. https://CRAN.R-project.org/package= MuMIn

Bates DM, Maechler M, Bolker B, Walker S (2015) Fitting linear mixed-effects models using lme4. J Stat Softw $67: 1-48$
Berglund H, Jonsson BG (2005) Verifying an extinction debt among lichens and fungi in northern Swedish boreal forests. Conserv Biol 19:338-348

Betts MG, Wolf C, Ripple WJ, Phalan B, Millers KA, Duarte A, Butchart SH, Levi T (2017) Global forest loss disproportionately erodes biodiversity in intact landscapes. Nature 547:441-444

Block WM, Finch DM, Brennan LA (1995) Single-species versus multiple-species approaches for management. In: Martin TE, Finch DM (eds) Ecology and management of neotropical migratory birds. Oxford University Press, New York, pp 461-476

Blowes SA, Supp SR, Antão LH, Bates A, Bruelheide H, Chase JM, Moyes F, Magurran A, McGill B, Myers-Smith IH (2019) The geography of biodiversity change in marine and terrestrial assemblages. Science 366:339-345

Bradshaw CJ, Warkentin IG, Sodhi NS (2009) Urgent preservation of boreal carbon stocks and biodiversity. Trends Ecol Evol 24:541-548

Carnus J-M, Parrotta J, Brockerhoff E, Arbez M, Jactel H, Kremer A, Lamb D, O'Hara K, Walters B (2006) Planted forests and biodiversity. J. Forest 104:65-77

Chase JM, Leibold MA (2002) Spatial scale dictates the productivity-biodiversity relationship. Nature 416:427-430

De Frenne P, Rodríguez-Sánchez F, Coomes DA et al (2013) Microclimate moderates plant responses to macroclimate warming. Proc Natl Acad Sci USA 110:18561-18565

Dettki H, Klintberg P, Esseen P-A (2000) Are epiphytic lichens in young forests limited by local dispersal? Ecoscience $7: 317-325$

Dormann CF, Elith J, Bacher S, Buchmann C, Carl G, Carré G, Marquéz JRG, Gruber B, Lafourcade B, Leitão PJ (2013) Collinearity: a review of methods to deal with it and a simulation study evaluating their performance. Ecography 36:27-46

Edman M, Gustafsson M, Stenlid J, Jonsson BG, Ericson L (2004a) Spore deposition of wood-decaying fungi: importance of landscape composition. Ecography 27:103-111

Edman M, Kruys N, Jonsson BG (2004b) Local dispersal sources strongly affect colonization patterns of wood-decaying fungi on spruce logs. Ecol Appl 14:893-901

Esseen PA, Ehnström B, Ericson L, Sjöberg K (1997) Boreal forests Ecol Bull 46:16-47

Fahrig L (2013) Rethinking patch size and isolation effects: the habitat amount hypothesis. J Biogeogr 40:1649-1663

Fenton NJ, Hylander K, Pharo EJ (2015) Bryophytes in forest ecosystems. In: Peh KSH, Corlett RT, Bergeron Y (eds) Routledge handbook of forest ecology. Routledge Handbooks Online, Abingdon, pp 255-265

Fox J (2003) Effect displays in R for generalised linear models. J Stat Softw 8:1-27

Frahm JP (2003) Climatic habitat differences of epiphytic lichens and bryophytes. Cryptog Bryol 24:3-14

Fridman J (2000) Conservation of forest in Sweden: a strategic ecological analysis. Biol Conserv 96:95-103

Gillman LN, Wright SD (2006) The influence of productivity on the species richness of plants: a critical assessment. Ecology 87:1234-1243

Gonthier DJ, Ennis KK, Farinas S, Hsieh H-Y, Iverson AL, Batáry P, Rudolphi TT, Cardinale BJ, Perfecto I (2014) 
Biodiversity conservation in agriculture requires a multiscale approach. Proc R Soc B 281:20141358

Grueber C, Nakagawa S, Laws R, Jamieson I (2011) Multimodel inference in ecology and evolution: challenges and solutions. J Evol Biol 24:699-711

Gustafsson L, Hylander K, Jacobson C (2004) Uncommon bryophytes in Swedish forests-key habitats and production forests compared. Forest Ecol Manag 194:11-22

Haddad NM, Brudvig LA, Clobert J, Davies KF, Gonzalez A, Holt RD, Lovejoy TE, Sexton JO, Austin MP, Collins CD (2015) Habitat fragmentation and its lasting impact on Earth's ecosystems. Sci Adv 1:e1500052

Hanski I (2015) Habitat fragmentation and species richness. J Biogeogr 42:989-993

Hedwall PO, Holmström E, Lindbladh M, Felton A (2019) Concealed by darkness: how stand density can override the biodiversity benefits of mixed forests. Ecosphere 10:e02835

Hijmans RJ (2017) raster: Geographic Data Analysis and Modeling. $\mathrm{R}$ package version 2.6-7, https://CRAN.Rproject.org/package=raster

Hodgson JA, Moilanen A, Wintle BA, Thomas CD (2011) Habitat area quality and connectivity: striking the balance for efficient conservation. J Appl Ecol 48:148-152

Isbell F, Gonzalez A, Loreau M, Cowles J, Díaz S, Hector A, Mace GM, Wardle DA, O'Connor MI, Duffy JE (2017) Linking the influence and dependence of people on biodiversity across scales. Nature 546:65-72

Johansson V, Ranius T, Snäll T (2012) Epiphyte metapopulation dynamics are explained by species traits, connectivity and patch dynamics. Ecology 93:235-241

Jönsson MT, Edman M, Jonsson BG (2008) Colonization and extinction patterns of wood-decaying fungi in a boreal oldgrowth Picea abies forest. J Ecol 96:1065-1075

Kouki J, Löfman S, Martikainen P, Rouvinen S, Uotila A (2001) Forest fragmentation in Fennoscandia: linking habitat requirements of wood-associated threatened species to landscape and habitat changes. Scand J For Res 16:27-37

Kouki J, Hyvärinen E, Lappalainen H, Martikainen P, Similä M (2012) Landscape context affects the success of habitat restoration: large-scale colonization patterns of saproxylic and fire-associated species in boreal forests. Divers Distrib 18:348-355

Lassauce A, Paillet Y, Jactel H, Bouget C (2011) Deadwood as a surrogate for forest biodiversity: meta-analysis of correlations between deadwood volume and species richness of saproxylic organisms. Ecol Indic 11:1027-1039

Lindenmayer DB, Franklin JF (2002) Conserving forest biodiversity: a comprehensive multiscaled approach. Island Press, Washington

Lõhmus A, Lõhmus P (2011) Old-forest species: the importance of specific substrata vs. stand continuity in the case of calicioid fungi. Silva Fenn 45:1015-1039

Matlack GR (1994) Plant species migration in a mixed-history forest landscape in eastern North America. Ecology 75:1491-1502

Mežaka A, Brūmelis G, Piterāns A (2012) Tree and stand-scale factors affecting richness and composition of epiphytic bryophytes and lichens in deciduous woodland key habitats. Biodiv Conserv 21:3221-3241
Michanek G, Bostedt G, Ekvall H, Forsberg M, Hof AR, De Jong J, Rudolphi J, Zabel A (2018) Landscape planningpaving the way for effective conservation of forest biodiversity and a diverse forestry? Forests 9:523

Morecroft MD, Crick HQ, Duffield SJ, Macgregor NA (2012) Resilience to climate change: translating principles into practice. J Appl Ecol 49:547-551

Newbold T, Hudson LN, Arnell AP, Contu S, De Palma A, Ferrier S, Hill SL, Hoskins AJ, Lysenko I, Phillips HR (2016) Has land use pushed terrestrial biodiversity beyond the planetary boundary? A global assessment. Science 353:288-291

Nicholson E, Possingham HP (2006) Objectives for multiplespecies conservation planning. Conserv Biol 20:871-881

Nilsson SG (1992) Forests in the temperate-boreal transitionnatural and man-made features. In: Hansson L (ed) Ecological principles of nature conservation. Elsevier, London, pp 373-393

Nitare J (2019) Skyddsvärd skog. Naturvårdsarter och andra kriterier för naturvärdesbedömning, Swedish Forest Agency, Jönköping

Nordén B, Appelqvist T (2001) Conceptual problems of ecological continuity and its bioindicators. Biodiv Conserv 10:779-791

Nordén B, Larsson KH (2000) Basidiospore dispersal in the oldgrowth forest fungus Phlebia centrifuga (Basidiomycetes). Nord J Bot 20:215-219

Nordén J, Penttilä R, Siitonen J, Tomppo E, Ovaskainen O (2013) Specialist species of wood-inhabiting fungi struggle while generalists thrive in fragmented boreal forests. J Ecol 101:701-712

Nordén J, Åström J, Josefsson T, Blumentrath S, Ovaskainen O, Sverdrup-Thygeson A, Nordén B (2018) At which spatial and temporal scales can fungi indicate habitat connectivity? Ecol Indic 91:138-148

Ohlson M, Söderström L, Hörnberg G, Zackrisson O, Hermansson J (1997) Habitat qualities versus long-term continuity as determinants of biodiversity in boreal old-growth swamp forests. Biol Conserv 81:221-231

Oksanen J, Blanchet F, Friendly M, Kindt R, Legendre P, McGlinn D, Minchin P, O'Hara R, Simpson G, Solymos P (2018) vegan: Community Ecology Package. R package version 2(5-2):2018

Östlund L, Zackrisson O, Axelsson A-L (1997) The history and transformation of a Scandinavian boreal forest landscape since the 19th century. Can J For Res 27:1198-1206

Paillet Y, Bergès L, Hjältén J, Ódor P, Avon C, BernhardtRomermann M, Bijlsma RJ, De Bruyn L, Fuhr M, Grandin U (2010) Biodiversity differences between managed and unmanaged forests: meta-analysis of species richness in Europe. Conserv Biol 24:101-112

Paltto H, Nordén B, Götmark F, Franc N (2006) At which spatial and temporal scales does landscape context affect local density of Red Data Book and Indicator species? Biol Conserv 133:442-454

Perhans K, Gustafsson L, Jonsson F, Nordin U, Weibull H (2007) Bryophytes and lichens in different types of forest set-asides in boreal Sweden. Forest Ecol Manag 242:374-390

Pianka ER (1966) Latitudinal gradients in species diversity: a review of concepts. Am Nat 100:33-46 
Poiani KA, Richter BD, Anderson MG, Richter HE (2000) Biodiversity conservation at multiple scales: functional sites landscapes and networks. Bioscience 50:133-146

Pouska V, Macek P, Zíbarová L (2016) The relation of fungal communities to wood microclimate in a mountain spruce forest. Fungal Ecol 21:1-9

Powell MJ (2009) The BOBYQA algorithm for bound constrained optimization without derivatives. Technincal Report NA2009/06, University of Cambridge, Cambridge

R Development Core Team (2015) R: A language and environment for statistical computing. The R Foundation for Statistical Computing, Vienna

Ranius T, Snäll T, Nordén J (2019) Importance of spatial configuration of deadwood habitats in species conservation. Conserv Biol 33:1205-1207

Reese H, Nilsson M, Pahlén TG, Hagner O, Joyce S, Tingelöf U, Egberth M, Olsson H (2003) Countrywide estimates of forest variables using satellite data and field data from the national forest inventory. Ambio 32:542-549

Roberge J-M, Öhman K, Lämås T, Felton A, Ranius T, Lundmark T, Nordin A (2018) Modified forest rotation lengths: long-term effects on landscape-scale habitat availability for specialized species. J Enviro Manage 210:1-9

Rubene D, Schroeder M, Ranius T (2017) Effectiveness of local conservation management is affected by landscape properties: species richness and composition of saproxylic beetles in boreal forest clearcuts. Forest Ecol Manag 399:54-63

Rudolphi J, Gustafsson L (2011) Forests regenerating after clear-cutting function as habitat for bryophyte and lichen species of conservation concern. PLoS ONE 6:e18639

Ruete A, Fritz Ö, Snäll T (2014) A model for non-equilibrium metapopulation dynamics utilizing data on species occupancy patch ages and landscape history. J Ecol 102:678-689

Scott JM, Davis FW, McGhie RG, Wright RG, Groves C, Estes J (2001) Nature reserves: do they capture the full range of America's biological diversity? Ecol Appl 11:999-1007

Siitonen J, Penttilä R, Kotiranta H (2001) Coarse woody debris polyporous fungi and saproxylic insects in an old-growth spruce forest in Vodlozero National Park Russian Karelia. Ecol Bull 49:231-242

Snäll T, Ribeiro P Jr, Rydin H (2003) Spatial occurrence and colonisations in patch-tracking metapopulations: local conditions versus dispersal. Oikos 103:566-578
Staniaszek-Kik M, Chmura D, Żarnowiec J (2019) What factors influence colonization of lichens liverworts mosses and vascular plants on snags? Biologia 74:375-384

Stokland JN, Siitonen J (2012) Species diversity of saproxylic organisms. In: Stokland JN, Siitonen J, Jonsson BG (eds) Biodiversity in dead wood. Cambridge University Press, Cambridge, pp 248-274

Sverdrup-Thygeson A, Gustafsson L, Kouki J (2014) Spatial and temporal scales relevant for conservation of deadwood associated species: current status and perspectives. Biodiv Conserv 23:513-535

Thrush SF, Hewitt JE, Lohrer AM, Chiaroni LD (2013) When small changes matter: the role of cross-scale interactions between habitat and ecological connectivity in recovery. Ecol Appl 23:226-238

Timonen J, Gustafsson L, Kotiaho JS, Mönkkönen M (2011a) Are woodland key habitats biodiversity hotspots in boreal forests? CEE 9:SR81

Timonen J, Gustafsson L, Kotiaho JS, Mönkkönen M (2011b) Hotspots in cold climate: conservation value of woodland key habitats in boreal forests. Biol Conserv 144:2061-2067

Varela E, Verheyen K, Valdés A, Soliño M, Jacobsen JB, De Smedt P, Ehrmann S, Gärtner S, Górriz E, Decocq G (2018) Promoting biodiversity values of small forest patches in agricultural landscapes: ecological drivers and social demand. Sci Total Environ 619:1319-1329

Wijk S (2017) Biologisk mångfald i nyckelbiotoper: resultat från inventeringen. Uppföljning av biologisk mångfald 2009-2015. Report 2017/4. Swedish Forest Agency, Jönköping

Wintle BA, Kujala H, Whitehead A, Cameron A, Veloz S, Kukkala A, Moilanen A, Gordon A, Lentini PE, Cadenhead NC (2019) Global synthesis of conservation studies reveals the importance of small habitat patches for biodiversity. PNAS 116:909-914

With KA (2004) Metapopulation dynamics: perspectives from landscape ecology. In: Hanski I, Gaggiotti OE (eds) Ecology genetics and evolution of metapopulations. Elsevier Academic Press, New York, pp 23-44

Zinko U (2004) Plants go with the flow: predicting spatial distribution of plant species in the boreal forest. Dissertation, Umeå University

Publisher's Note Springer Nature remains neutral with regard to jurisdictional claims in published maps and institutional affiliations. 